\title{
Doğal Gaz Yakıtlı Bir Yanma Odasında Hava ve Yakıt Hızlarının Sıcaklık, Entalpi ve Entropi Üzerindeki Etkisinin İncelenmesi
}

\author{
Barış İŞYARLAR $^{1 *}$, İbrahim KIRBAȘ ${ }^{2}$ \\ ${ }^{I}$ Ordu Üniversitesi, Teknik Bilimler Meslek Yüksekokulu, 52200, Ordu \\ ${ }^{2}$ Mehmet Akif Ersoy Üniversitesi, Teknik Bilimler Meslek Yüksekokulu, 15100, Burdur
}

Geliş tarihi/Received 21.11.2014

Düzeltilerek geliş tarihi/Received in revised form 20.04.2015

Kabul tarihi/Accepted 05.05.2015

\section{$\ddot{O z e t}$}

Alternatif enerji kaynaklarından olan doğal gazın kullanımı 2000’li yıllardan itibaren oldukça yaygınlaşmış̧ır. Doğal gazın başlıca kullanım alanları konut ısıtması, pişirme, sanayi ve elektrik santralleridir. Yaygın olarak kullanılmasından dolayı doğal gazın daha verimli kullanımı ve yakıt ekonomisi sağlamak için doğal gazın yanması üzerine çeşitli araştırmalar yapılmaktadır. Deneysel olarak yapılan çalışmaların zaman alması ve deneysel çalışmalarda karşılaşılan sorunlar nedeniyle çok fazla tercih edilmemektedir. Bu nedenle yanma olayın benzetim yapabilen programlar kullanarak çalışmalar kuramsal olarak yapılmaktadır. Bu çalışma, Fluent 6.0 paket programını kullanarak doğal gaz yakıtlı bir yanma odası içinde gerçekleşen yanma olayındaki termodinamik hal büyüklüklerinin incelenmesi üzerinedir. Öncelikle program kullanılarak doğal gaz yakıtlı bir yanma odası tasarlanmıştır. Daha sonra çeşitli parametreler ele alınmış, bu parametrelerin değişimlerinin sonucu olarak da, yanma odası içerisindeki sicaklık, entalpi, entropi değerleri incelenmiştir.

Anahtar kelimeler: Doğal Gaz, Yanma, Yanma Odaları, Termodinamik Özellikler

\section{Investigation of the Effect on the Temperature, Enthalpy and Entropy of the Air and Fuel Speed in Natural Gas-Fired Combustion Chamber}

\begin{abstract}
The use of natural gas as alternative energy source has become fairly widespread since the 2000's. The main application areas of natural gas are the hosing heating, the cooking, the industry and the power plants. Various researches on the combustion of natural gas have been conducted to ensure the more efficient use of natural gas and fuel economy due to the widespread use. Experimental studies aren't too much preferred due to taking a long time and the problems encountered during experimental studies. Therefore, the studies on combustion chambers have been generally conducted theoretically by using a program which simulates to combustion. Using Fluent 6.0 package program in this study, the combustion which takes place in a natural gas-fired combustion chamber is on analysis of the thermodynamic state. The first, the natural gas-fired combustion chamber has been designed by using the Fluent 6.0 package program. The later, the temperature, enthalpy and entropy values in the combustion chamber have been investigated as a result of the changing these parameters by considering various parameters
\end{abstract}

Keywords: Natural Gas, Combustion, Combustion Chambers, Thermodynamic Properties

\footnotetext{
*Barış İŞYARLAR, isyarlar@hotmail.com, Tel: (0452) 2334159
} 


\section{Giriş}

İçerisinde esas olarak metan $\left(\mathrm{CH}_{4}\right)$ ve daha az oranda etan $\left(\mathrm{C}_{2} \mathrm{H}_{6}\right)$ ve propan $\left(\mathrm{C}_{3} \mathrm{H}_{8}\right)$ gazlar1 ağırlıklı olan doğal gaz oldukça temiz ve kaliteli sayılan bir gazdır (Aras, 1995). Hava ile karışımı daha kolay olan doğal gazın yanma verimi oldukça yüksektir (URL1, 2006; Küçükçalı, 1994). $1 \mathrm{~m}^{3}$ gazın yanması sonucu $8250 \mathrm{kcal}$ enerji açığa çıkar. Doğal gazın özgül ağırlığı $0.55 \mathrm{~kg} / \mathrm{m}^{3}$ civarındadır, aynı hacimdeki havadan yarı yarıya daha hafiftir. Doğal gazın tutuşma sıcaklığı $650{ }^{\circ} \mathrm{C}$ dir. Doğal gazın alev hızı $0.36 \mathrm{~m} / \mathrm{s}$ dir. Doğal gazın üst 1sıl değer aralığ $8750-9360 \mathrm{kcal} / \mathrm{m}^{3}$ dir. (URL2, 2015). Ayrıca doğal gaz tam yandığında, hidrojenle oksijenin tepkimesi sonucunda su buharı meydana gelir. Doğal gazın yanması sirasında, 1sının bir kısmı reaksiyon suyunun buharlaşması için harcanır. Doğal gazın yanması sonucu oluşan baca gazındaki su buharı oranı \% 16.9 civarındadır. Doğal gaz içerisinde kükürt bulunmadığından baca gazı sıcaklığ $56{ }^{\circ} \mathrm{C}$ 'ye kadar indirilebilir (Küçükçalı, 1998). Baca gazlarının 1sısından yararlanma olanağı sağlanırsa verim, üst 1sıl değerde \% 96-97 oranında gerçekleşebilmektedir (Telli, 1998; Öztürk, 1991; Uyarel, 1995).

Yanma odaları hakkında geçmişten günümüze kadar hem kuramsal, hem de deneysel olarak birçok çalışma yapılmıştır. Yanma odaları, oda geometrisinin yakıtın yanma oranı ve akışına etkisini incelemek için dizayn edilmiş yapilardır (Johansson ve Olsson, 1995). Soyhan ve Soruşbay, yanma odası şeklinin yanma performansına etkisini incelemiştir (Soyhan ve Soruşbay, 1996). Bu yapılan çalışmaların asıl amacı yanma veriminin artırılmasının yanında, yanma süresinin kısa zamanda gerçekleşmesini sağlamak, yanma sonucu ortaya çıkan çevreye zararlı gazların oluşmasını engellemek, yanma odasının daha toplu hale getirilmesini sağlamaktır.

Kimyasal reaksiyon 1sı transferine bağlı entropi üretimleri optimum dizayn koşullarının sağlanması için gerekli faktörlerdir. $\mathrm{Bu}$ yüzden yanma odas1 dizaynında minimum toplam entropi üretimi sağlayacağı şekilde ve maksimum sıcaklık ve ölçülerde dizayn edilmesi önerilmektedir (Arjmandi ve Amani, 2015).

Oksijen yetersizliği, yanmanın tam olmamasının nedenlerinden biridir. Yanma odasında tam yanma için gerekli oksijenden daha fazla oksijen olsa bile, yanma tam olmayabilir. Bunun nedenlerinden biri, yakıtın ve oksijenin bir arada olduğu süre içinde yeterince karışamamasıdır (Çengel ve Boles, 1996). Yanmanın tam olmamasının bir başka nedeni de yüksek sıcaklıklarda önem kazanan ayrışmadır (Turns, 2000). Karbonmonoksit (CO); yetersiz hava, hava ve yakıt karışımının kötü olması veya yeterli büyüklükte boyutlandırılmamış yanma odası nedeniyle oluşan eksik yanma neticesinde meydana gelmektedir (Keating, 1993).

Hüseyin Topal, alışılmış 1zgaralı kalorifer kazanlarının yanma odasında ve 1zgara sistemlerinde yapılan bazı değişikliklerin kazan ısıl verim ve emisyon davranışına etkisini deneysel olarak incelemiştir. $\mathrm{Bu}$ modifikasyonların kazan isıl verimlerinin artırılmasında ve yanmadan kaynaklanan emisyonların da azaltılmasında oldukça etken olduğunu görmüştür (Topal, 1992).

Chen ve Lv dizel motorun yanma odasinın çok amaçlı optimizasyonu olarak yaptıkları çalışmada hava/yakıt karıştırma, yanma ve emisyon oluşumu gibi parametreleri optimizasyon parametreleri olarak seçmişlerdir. Yanma odas1 simülasyonlarından gelen sayısal sonuçlar 8.9 L Cummins Dizel motor üzerinde yürütülen test ile karşılaştırılmıştır. En çok araştırılan çalışma koşulları için, emisyon simüle sonuçları test verileri ile iyi bir uyum gösterdiğini belirlemişlerdir (Chen ve $\mathrm{Lv}, 2014$ ).

İlbaş vd. (2006) yapmış oldukları çalışmalarında gaz türbini yanma odası içerisindeki türbülanslı reaksiyon akışını, stokiometrik karışım oranlarında iki farklı hidrokarbon yakit (metan ve propan) ile hidrojen yanması için sonlu hacimler tekniği ile çözüm yapan sayısal akışkan dinamiği çözücüsü FLUENT 6.1.22 programı 
kullanılarak incelemişlerdir. Bütün çalışma durumlarında yakıtın yanma odası çıkışında tamamen tükendiğini görmüşlerdir. Böylelikle, yakıtın tamamen yandığı ve çalışılan durumların bütününde tam yanma olduğu gözlemlemişlerdir. Aynı zamanda hidrojenin, metan ve propana göre daha çabuk tükendiğini belirtmişlerdir (İlbaş vd., 2006).

Yapılan çalışmalardan da anlaşılacağı gibi bazı durumlarda deneysel çalışmaların zorlukları ve zaman gibi sorunlar simülasyon programları kullanılarak çözüm bulmaktadır.

$\mathrm{Bu}$ çalışmada Fluent 6.0 paket program sayesinde doğalgaz yakıtlı bir yanma odasının modeli oluşturulacaktır. Bu yanma odasında yakıt (doğal gaz) ve hava hızlarının sıcaklık, entalpi ve entropi üzerindeki etkileri incelenecektir.

\section{Materyal ve Yöntem}

Fluent, 1sı transferi, kütle transferi, akışkanlar dinamiği, kimyasal reaksiyon ve bunun gibi olayların simülasyonunu yapan, kütle korunumu, momentum korunumu, enerji korunumu, türbülans transport ve karışım denklemlerini kontrol hacmi tekniği kullanarak ayrık veya birleşik çözüm yöntemi ile sayısal olarak çözebilen, mühendislik uygulamalarında kullanılan genel amaçlı bir bilgisayar programıdır (İsyarlar, 2007).

Bahsi geçen incelemelerin yapılabilmesi için bir yanma odası tasarlanmış ve yanma olayı üzerinde hava ve yakıtın hızları değiştirilerek, diğer parametreler ise sabit tutularak hava ve yakıt hızlarının yanma olayı üzerindeki etkisi incelenmiştir. Yanma odası Şekil 1'de verilmiştir.

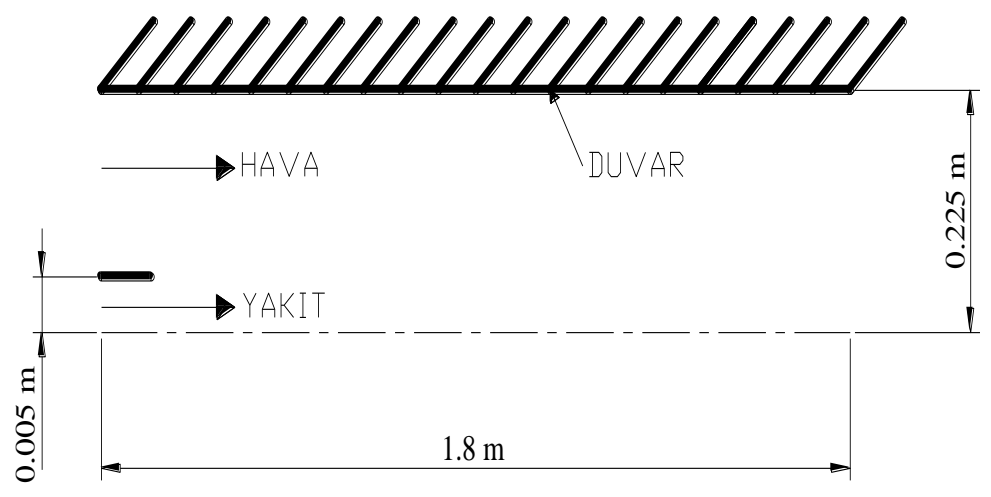

Şekil 1. Yanma odası

Hava ve yakıt hızlarının yanma olayı üzerindeki etkisinin incelenmesi için ilk önce standart bir durum seçilmiştir. Belirlenen bu standart duruma göre hava ve yakıt yanma odasına aynı sicaklıkta (300 K) girmektedir. Duvar sicaklığı adyabatik sicaklık olarak seçilmiştir. Yakıt hızı ise $2 \mathrm{~m} / \mathrm{s}, 4 \mathrm{~m} / \mathrm{s}, 6 \mathrm{~m} / \mathrm{s}$,
$8 \mathrm{~m} / \mathrm{s}, 12 \mathrm{~m} / \mathrm{s}$ alınmıştır. Yakıt hızına bağlı olarak havanın hızı Tablo 1'de verilmiștir. Ayrica yanma tepkimesinin stokiometrik miktarda hava kullanımıyla gerçekleştiği düşünülmüş ve yanmanın tam olduğu kabul edilmiştir.

Tablo 1. Yakıt hızına bağlı olarak hava hızı

\begin{tabular}{|c|c|c|c|c|c|}
\hline Teorik hava yüzdesi (\%) & \multicolumn{5}{|c|}{ Yakıt hızları (m/s) } \\
\hline 100 & 2 & 4 & 6 & 8 & 12 \\
\hline Hava hızları (m/s) & 0.0148 & 0.020 & 0.031 & 0.041 & 0.0889 \\
\hline
\end{tabular}




\section{Bulgular ve İrdeleme}

Yapılan bu çalışmada, doğal gaz yakıtlı bir yanma odası tasarlanmış olup ve bu yanma odası üzerinde çeşitli parametrelerin değiştirilmesi ile bu parametrelerin sıcaklık, entalpi ve entropi üzerindeki etkisi incelenmiştir.

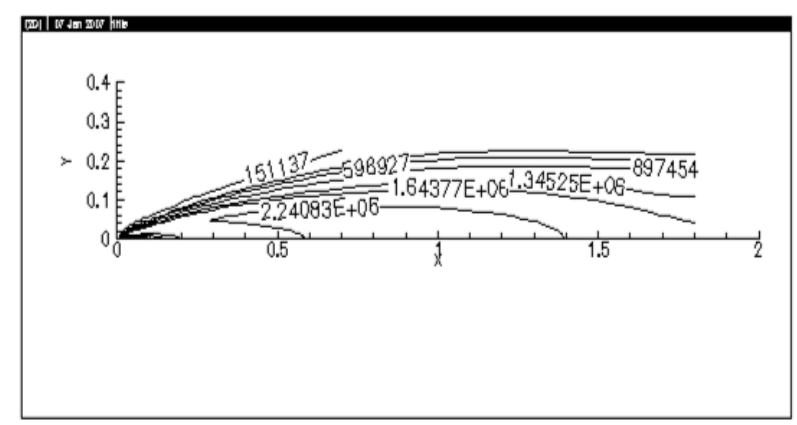

Şekil 2. Yakıt hızı $2 \mathrm{~m} / \mathrm{s}$ olduğunda entalpi dağılımı

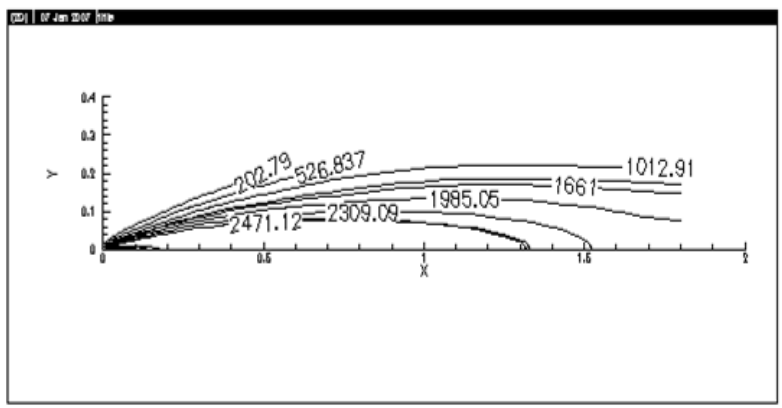

Şekil 3. Yakıt hızı $2 \mathrm{~m} / \mathrm{s}$ olduğunda entropi dağılımı

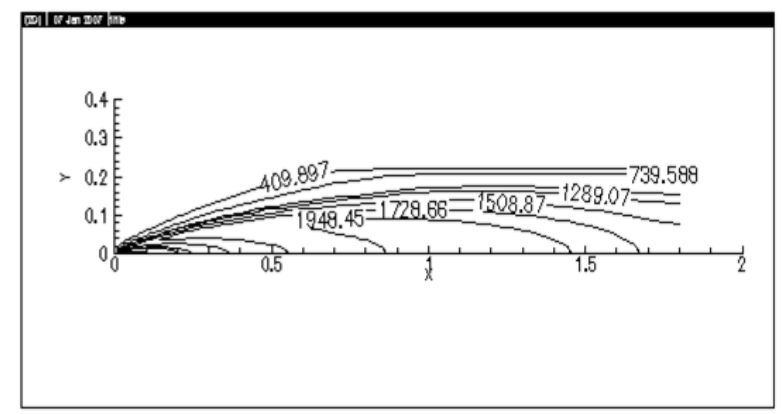

Şekil 4. Yakıt hızı $2 \mathrm{~m} / \mathrm{s}$ olduğunda sıcaklık dağılımı

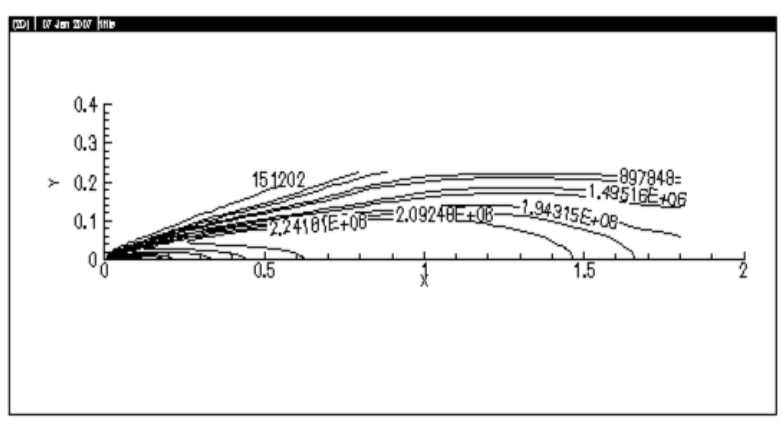

Şekil 5. Yakıt hızı $4 \mathrm{~m} / \mathrm{s}$ olduğunda entalpi dağılımı

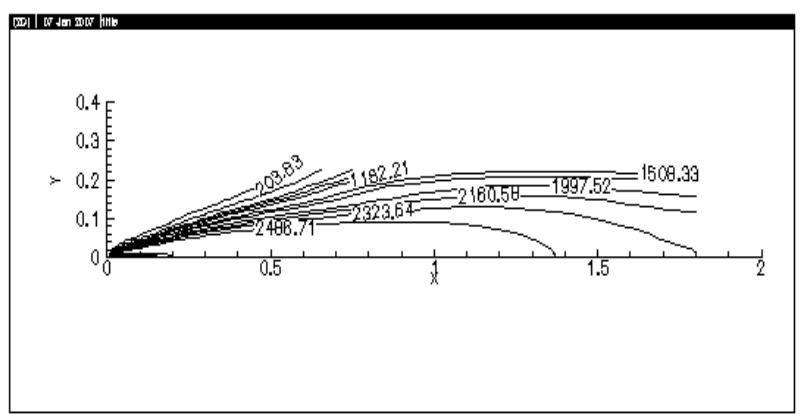

Şekil 6. Yakıt hızı $4 \mathrm{~m} / \mathrm{s}$ olduğunda entropi dağılımı

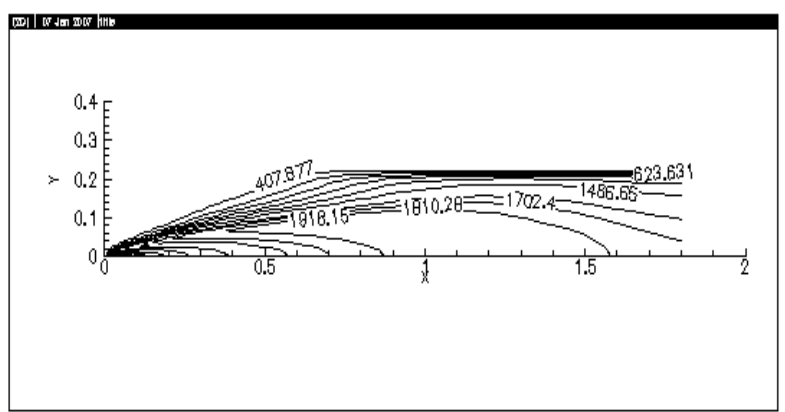

Şekil 7. Yakıt hızı $4 \mathrm{~m} / \mathrm{s}$ olduğunda sıcaklık dağılımı

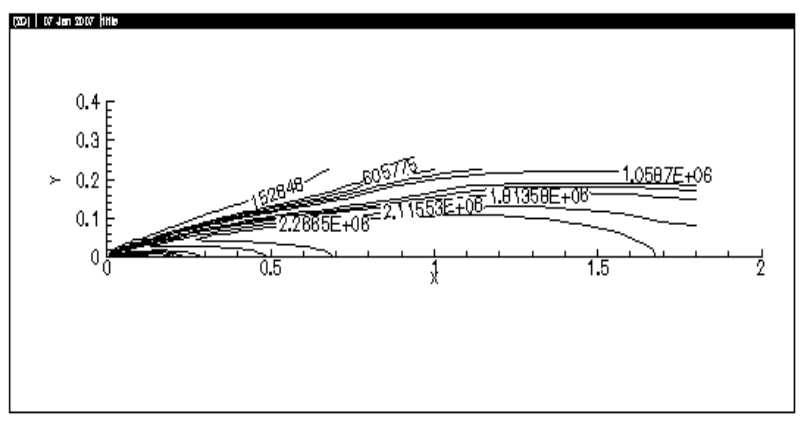

Şekil 8. Yakıt hızı $6 \mathrm{~m} / \mathrm{s}$ olduğunda entalpi dağılımı 


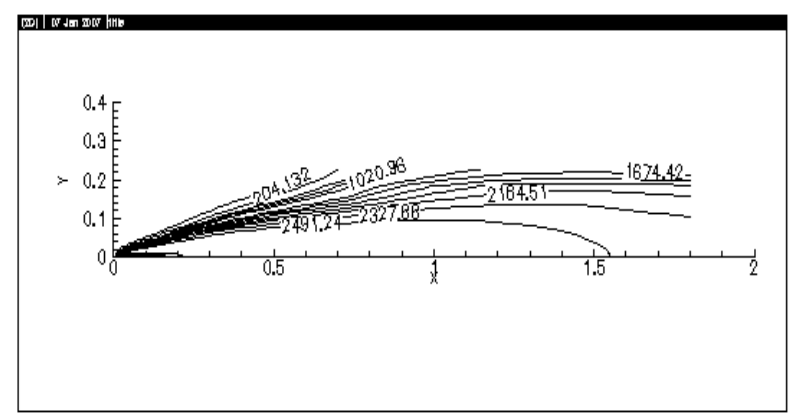

Şekil 9. Yakıt hızı $6 \mathrm{~m} / \mathrm{s}$ olduğunda entropi dağılımı

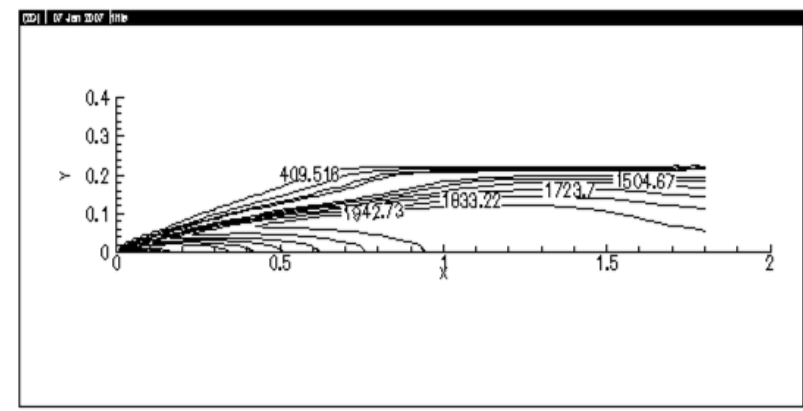

Şekil 10. Yakıt hızı $6 \mathrm{~m} / \mathrm{s}$ olduğunda sıcaklık dağılımı

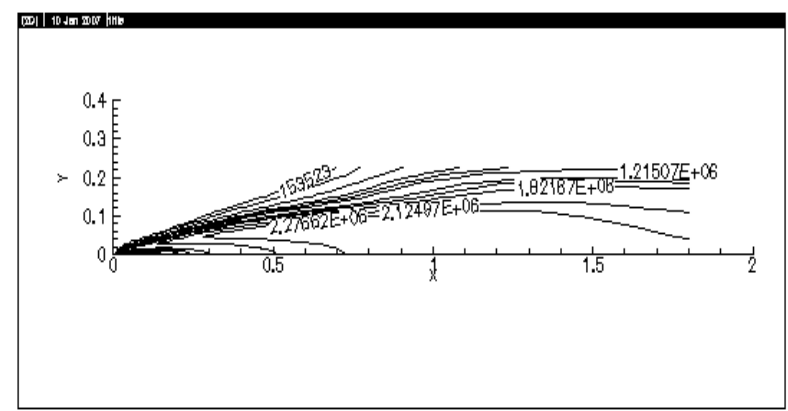

Şekil 11. Yakıt hızı $8 \mathrm{~m} / \mathrm{s}$ olduğunda entalpi dağılımı

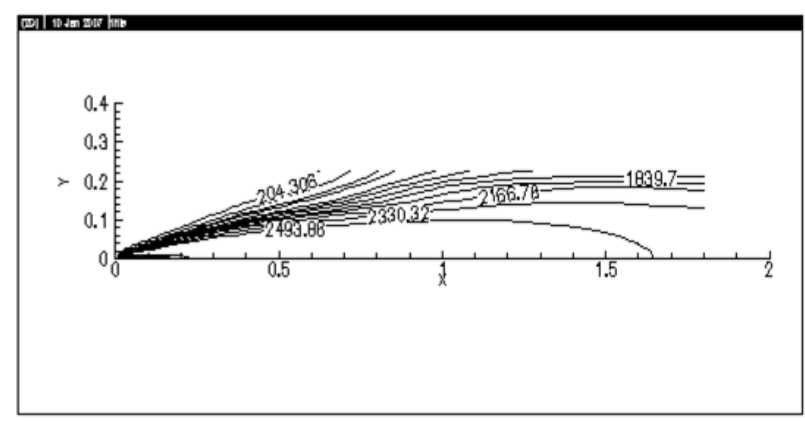

Şekil 12. Yakıt hızı $8 \mathrm{~m} / \mathrm{s}$ olduğunda entropi dağılımı

Yukarıdaki şekiller incelendiğinde kabul edilen yakit ve hava hizlarından elde edilen

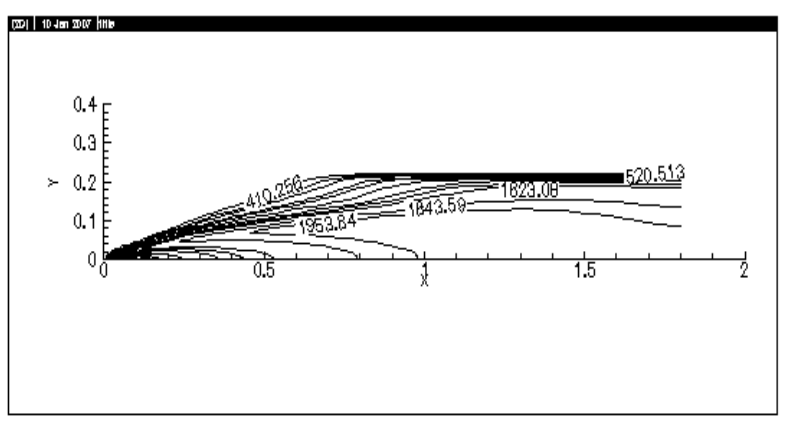

Şekil 13. Yakıt hızı $8 \mathrm{~m} / \mathrm{s}$ olduğunda sıcaklık dağılımı

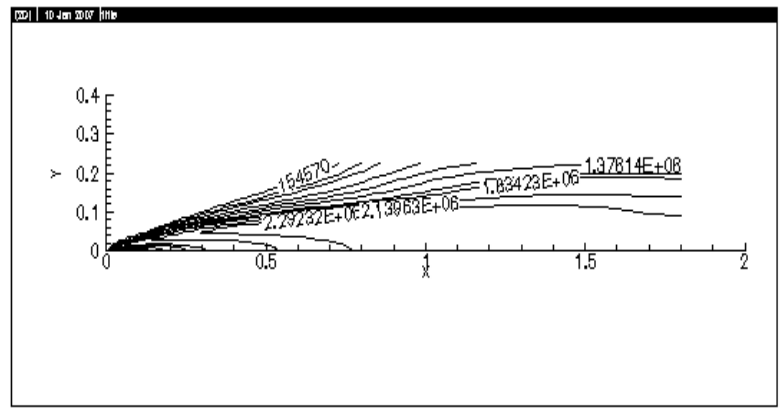

Şekil 14. Yakıt hızı $12 \mathrm{~m} / \mathrm{s}$ olduğunda entalpi dağılımı

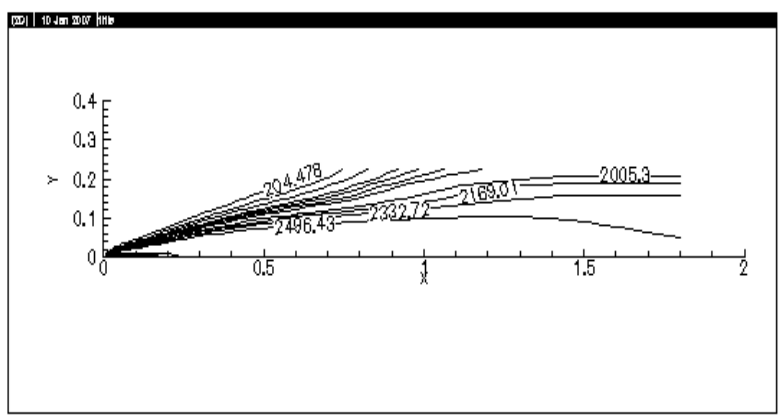

Şekil 15. Yakıt hızı $12 \mathrm{~m} / \mathrm{s}$ olduğunda entropi dağılımı

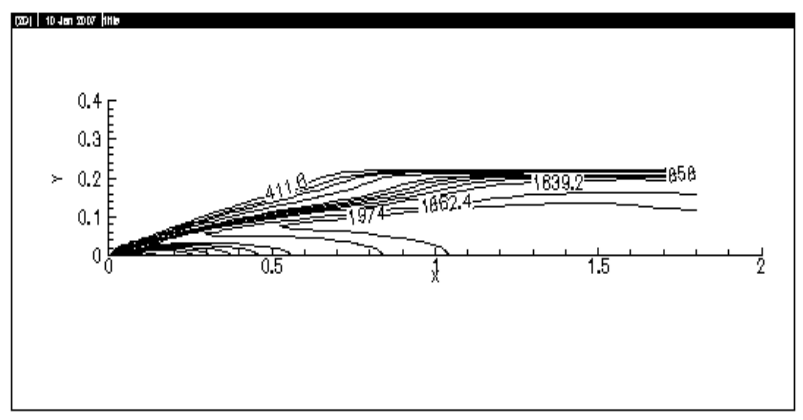

Şekil 16. Yakıt hızı $12 \mathrm{~m} / \mathrm{s}$ olduğunda sıcaklık dağılımı

entalpi, entropi ve sıcaklık değerleri Tablo 2 'de verilmiştir. 
Tablo 2. Kabul edilen yakıt ve hava hızlarındaki entalpi, entropi ve sıcaklık değerleri

\begin{tabular}{|c|c|c|c|c|c|c|c|}
\hline \multirow{2}{*}{$\begin{array}{c}\text { Yakıt } \\
\text { h1z1 } \\
(\mathrm{m} / \mathrm{s})\end{array}$} & \multirow{2}{*}{$\begin{array}{c}\text { Hava } \\
\text { h1z1 } \\
(\mathrm{m} / \mathrm{s})\end{array}$} & \multicolumn{2}{|c|}{$\begin{array}{l}\text { Entalpi } \\
(\mathrm{kJ} / \mathrm{kg})\end{array}$} & \multicolumn{2}{|c|}{$\begin{array}{c}\text { Entropi } \\
(\mathrm{kJ} / \mathrm{kmolK})\end{array}$} & \multicolumn{2}{|c|}{$\begin{array}{c}\text { S1caklık } \\
(\mathrm{K})\end{array}$} \\
\hline & & En düşük & En yüksek & En düşük & En yüksek & En düşük & En yüksek \\
\hline 2 & 0.0148 & 151.13 & 2240 & 202.79 & 2471 & 409.89 & 1948 \\
\hline 4 & 0.020 & 151.20 & 2241 & 203.83 & 2486 & 407.87 & 1916 \\
\hline 6 & 0.031 & 152.84 & 2266 & 204.13 & 2491 & 409.51 & 1942 \\
\hline 8 & 0.041 & 153.52 & 2276 & 204.30 & 2493 & 410.25 & 1953 \\
\hline 12 & 0.0889 & 154.57 & 2292 & 204.47 & 2496 & 411.60 & 1974 \\
\hline
\end{tabular}

\section{Sonuçlar}

Şekillerden de görüleceği üzere sicaklığın en yüksek olduğu yakıt hızı $12 \mathrm{~m} / \mathrm{s}$ 'dir. Yakıt bu hızda iken sıcaklık değeri Şekil 16'dan 1974 K olduğu okunmuştur. Şekil 4'e bakıldığında yakıt hızı $2 \mathrm{~m} / \mathrm{s}$ olduğu durumda sicaklık 1948 K değerini almıştır. Şekil 14 ve Şekil 15 'de $12 \mathrm{~m} / \mathrm{s}$ hızındaki entalpi ve entropi değerleri sirasiyla $2292 \mathrm{~kJ} / \mathrm{kg}$ ve 2496 $\mathrm{kJ} / \mathrm{kmolK}$ olmuştur. $2 \mathrm{~m} / \mathrm{s}$ yakıt hızı için bu değerler Şekil 2 ve Şekil 3'te $2240 \mathrm{~kJ} / \mathrm{kg}$ ve $2471 \mathrm{~kJ} / \mathrm{kmolK}$ olarak tespit edilmiştir.

Sonuç olarak yakıt ve havanın uygun hızlarda yanma odasina girmesi ile yakıt ve hava hızlarının artması durumunda, en yüksek yanma sıcaklığı, entalpisi ve entropisi elde edilmektedir. Arjmandi, ve Amani, (2015) yaptıkları çalışmada farklı yakıt hızlarının entropi üretimine etkisini incelemişler ve artan yakıt hızıyla entropi üretiminin arttığını belirlemişlerdir. Yapılan bu çalışma literatür ile uyumluluk göstermektedir. Elde edilen değerlere ve şekillere bakıldığında sıcaklığın, entalpinin ve entropinin en yüksek ve düzgün oluştuğu yakıt hızı 12 m/s'dir. Burada önemli olan yakit ve havanın uygun hizlarda yanma odasına gönderilmiş olmasıdır. Görüldüğü gibi en iyi yanma yüksek hızlarda gerçekleşmektedir.

\section{Kaynaklar}

Aras, H. ve Taner, K., 1995. Doğal Gaz Kullanan Tesislerde Atık Isıdan Faydalanma. Uluslararası Doğal Gaz Kongresi Bildiriler Kitabı, Ankara, 81$83 \mathrm{~s}$.
Arjmandi, H.R. ve Amani, E., 2015. A numerical investigation of the entropy generation in and thermodynamic optimization of a combustion chamber, Energy 81, 706-718.

Chen, Y., Lv, L., 2014. The Multi-objective Optimization of Combustion Chamber of DI Diesel Engine by NLPQL Algorithm, Applied Thermal Engineering, 73, 1330-1337.

Çengel, Y.A. ve Boles, M.A., 1996. Mühendislik Yaklaşımıyla Termodinamik, Literatür Yayıncılık, ISBN: 9789758431915.

İlbaş, M., Yılmaz, İ. ve Özkan, F., 2006. Gaz Türbini Yanma Odasında Hidrojen ve Hidrokarbon Yanmasının Modellenmesi ve $\mathrm{No}_{\mathrm{x}}$ Oluşumunun İncelenmesi, Mühendis ve Makine, 47, 559, 35-44.

İsyarlar, B., 2007. Doğal Gaz Yakıtlı Bir Yanma Odasında Termodinamik Hal Büyüklüklerinin Analizi. Yüksek Lisans Tezi, Gazi Üniversitesi Fen Bilimleri Enstitüsü, Ankara, 40-42s.

Johansson, B., ve Olsson, K., 1995. Combustion Chambers for Natural Gas SI Engines Part I: Fluid Flow and Combustion, International Congress and Exposition Detroit, Michigan February 27-March 2.

Keating, E.L., 1993. Applied Combustion, Marcel Dekker Inc., USA. 
Küçükçalı, R., 1994. Doğal Gazın Tanımı, Isısan Çalışmaları, 75: 8-10s.

Küçükçalı, R., 1998. Doğal Gazın Tanıtımı, Isısan Çalışmaları, 172: 8-11s.

Öztürk, S., 1991. Doğalgaz ve Uygulamaları, Sistem Ofset, Ankara, 1-13s, 47s, 8099s.

Soyhan, H.S. ve Soruşbay, C., 1996. Combustion modelling in Dedicated Natural Gas Engines, Mathemahcal \& Computational Applications, Vol I, NO. 1,PI' 119-125.

Telli, Z,K., 1998. Termodinamik Semineri, Palme Yayıncılık, Ankara, 1-65s.

Topal, H., 1992. Izgaralı Kazanlarda Yanma Odasındaki Yapısal Değişikliklerin Kazan Is1l Performans ve Emisyon Davranışına Etkisinin İncelenmesi. Yüksek Lisans Tezi, Gazi Üniversitesi Fen Bilimleri Enstitüsü, Ankara, 1-17s.
Turns, S.R., 2000. An Introduction to Combustion, McGraw-Hill, Inc., New York.

Uyarel, A.Y., 1995. Konut Gaz Tesisleri Gaz Kullanımı, Milli Eğitim Bakanlığı Yayınları., ISBN NO: 9751110181, Ankara, 30-41s, 50s, 65s.

URL-1, İstanbul Üniversitesi, 2006. Doğal Gazın Özellikleri ve Yanma Bilgileri http://www.istanbul.edu.tr/yerkure/Petr ol1.htm

URL-2， Doğal Gazın Özellikleri, 2015. http://www.kargaz.com.tr/trTR/dogalgazin-ozelliklerinelerdir/1848/Page.aspx 